\title{
Effect of the Type of Emulsifying Salt on Microstructure and Rheological Properties of "Requeijão Cremoso" Processed Cheese Spreads
}

\author{
Clarissa R. da Cunha, Maria Regina Alcântara, and Walkiria H. Viotto
}

\begin{abstract}
The role of different types of emulsifying salts-sodium citrate (TSC), sodium hexametaphosphate (SHMP), sodium tripolyphosphate (STPP) and tetrasodium pyrophosphate (TSPP)—on microstructure and rheology of "requeijão cremoso" processed cheese was determined. The cheeses manufactured with TSC, TSPP, and STPP behaved like concentrated solutions, while the cheese manufactured with SHMP exhibited weak gel behavior and the lowest values for the phase angle $\left(G^{\prime} / G^{\prime}\right)$. This means that SHMP cheese had the protein network with the largest amount of molecular interactions, which can be explained by its highest degree of fat emulsification. Rotational viscometry indicated that all the spreadable cheeses behaved like pseudoplastic fluids. The cheeses made with SHMP and TSPP presented low values for the flow behavior index, meaning that viscosity was more dependent on shear rate. Regarding the consistency index, TSPP cheese showed the highest value, which could be attributed to the combined effect of its high $\mathrm{pH}$ and homogeneous fat particle size distribution.
\end{abstract}

Keywords: fat emulsification, microstructure, peptization, rheology, spreadable processed cheese

\section{Introduction}

"Requeijão cremoso" is a traditional Brazilian spreadable processed cheese which presents a fluid consistency and a high fat content (minimum $55 \%$ on a dry weight basis), and can be essentially classified as an oil-in-water emulsion. Traditionally the product is made by the fusion of the fresh curd obtained by direct acidification of heated milk (after removal of the whey and washing), but some manufacturers also use curds obtained by lactic fermentation and/or rennet coagulation. The fusion is achieved through the addition of emulsifying salts (ESs), usually followed by the addition of cream and/or butter. The resulting mass is then cooked at 85 to $95^{\circ} \mathrm{C} / 2$ to $7 \mathrm{~min}$, and hot filled into plastic or glass jars.

"Requeijão cremoso" cheese is usually spread over toasts or cream crackers using a knife, and also used as a food ingredient for pizza and as a filling for stuffed foods (pasta, pies, nuggets, sandwiches, etc.). The product has increasing importance in the national market: from 2004 to 2007, its production increased 52\%, achieving $47000000 \mathrm{~kg}$ and placing it as the second most consumed cheese in Brazil (ABIQ 2008).

In processed cheeses, the type of ES influences the casein peptization and the degree of fat emulsification, parameters that affect the quality of the final product. Peptization, defined as the separation of the large hydrophobic aggregates of casein into smaller units during the heating and stirring of the mass, increases casein hydration, and exposes its polar and nonpolar groups, allowing

MS 20120049 Submitted 1/10/2012, Accepted 5/9/2012. Author da Cunha and Viotto are with the Dept. of Food Technology, Faculty of Food Engineering, State Univ. of Campinas - UNICAMP, P.O. Box 6121, Campinas-SP 13083-862, Brazil. Author Alcantara is with the Inst. of Chemistry, Univ. of São Paulo, P.O. Box 26077, São Paulo, SP 05599-970, Brazil. Direct inquiries to author da Cunha (E-mail: clareschke@uol.com.br). casein to act as an emulsifier at the water-oil interface (Zehren and Nusbaum 1992). The transformation of the casein network into a stable colloidal dispersion is accompanied by an increase in viscosity of the molten mass, and this phenomenon is known as cremification (Zehren and Nusbaum 1992; Guinee and others 2004).

Currently, citrates, monophosphates, and polyphosphates are widely used in the manufacture of processed cheese, and depending on the desired action they can be used alone or combined in different proportions (Berger and others 1989). The degree of hydration of the para-casein and the size distribution of the emulsified fat globules has considerable influence on the structure and rheology of the processed cheese (Guinee and others 2004). Understanding the effect of each salt on cheese rheological characteristics, such as the elastic and the viscous moduli, is important to explain the structure of the final product. Moreover, the knowledge of the flow behavior of the materials allows the correct selection of equipments (pumps and filling machines) and optimization of their operational conditions.

There are few studies on the role of ESs on the rheological characteristics of processed cheeses. Most of them include different raw materials, processing conditions and cheese composition, therefore leading to conflicting results (Dimitreli and others 2005; Dimitreli and Thomareis 2009; Sádlíkova and others 2010). The use of anhydrous ingredients makes it possible to use always the same source of protein and fat, avoiding variation in cheese composition and allowing cheese to be treated as a model system where the variables are limited and well known. This approach might be useful to provide a more general understanding about the effect of individual ESs on the rheology of processed cheeses.

The objective of the present study was to evaluate the role of different types of ES (sodium citrate [TSC], sodium hexametaphosphate [SHMP], sodium tripolyphosphate [STPP], and tetrasodium pyrophosphate [TSPP]) on the microstructure and rheological 
characteristics of "requeijão cremoso" cheese manufactured using anhydrous ingredients.

\section{Material and Methods}

\section{Processing of "requeijão cremoso" made from anhydrous} ingredients

The processed cheeses used in this study were the same as those described in an earlier study (Cunha and Viotto 2010), where the ingredients and manufacture conditions have been detailed, as well as the methods used to evaluate cheese composition and the degree of casein dissociation. The processed cheese manufacture flow diagram is shown in Figure 1.

\section{Microstructure}

Microstructure of processed cheeses was assessed using scanning electron microscopy. The samples were prepared using the method described by Marchesseau and others (1997), adapted to the conditions of "requeijão cremoso" cheese, as described by Gallina (2005). Initially the samples were placed in disposable syringes and the plunger carefully pushed down to form "threads" of processed cheese. The "threads" were fixed with $2.5 \%$ glutaraldehyde in a $0.1 \mathrm{M}$ phosphate buffer $(\mathrm{pH}$ 7.2) for $4 \mathrm{~h}$ at room temperature, then cut with a knife and fixed for more $9 \mathrm{~h}$, washed in $0.1 \mathrm{M}$ phosphate buffer and postfixed with $1 \% \mathrm{OsO}_{4}$ in $0.1 \mathrm{M}$ phosphate buffer for $8 \mathrm{~h}$. After further washing with $0.1 \mathrm{M}$ phosphate buffer, the samples were dehydrated in a graded series of ethanol $(50 \%, 70 \%, 90 \%, 95 \%$, and $100 \%)$, followed by $100 \%$

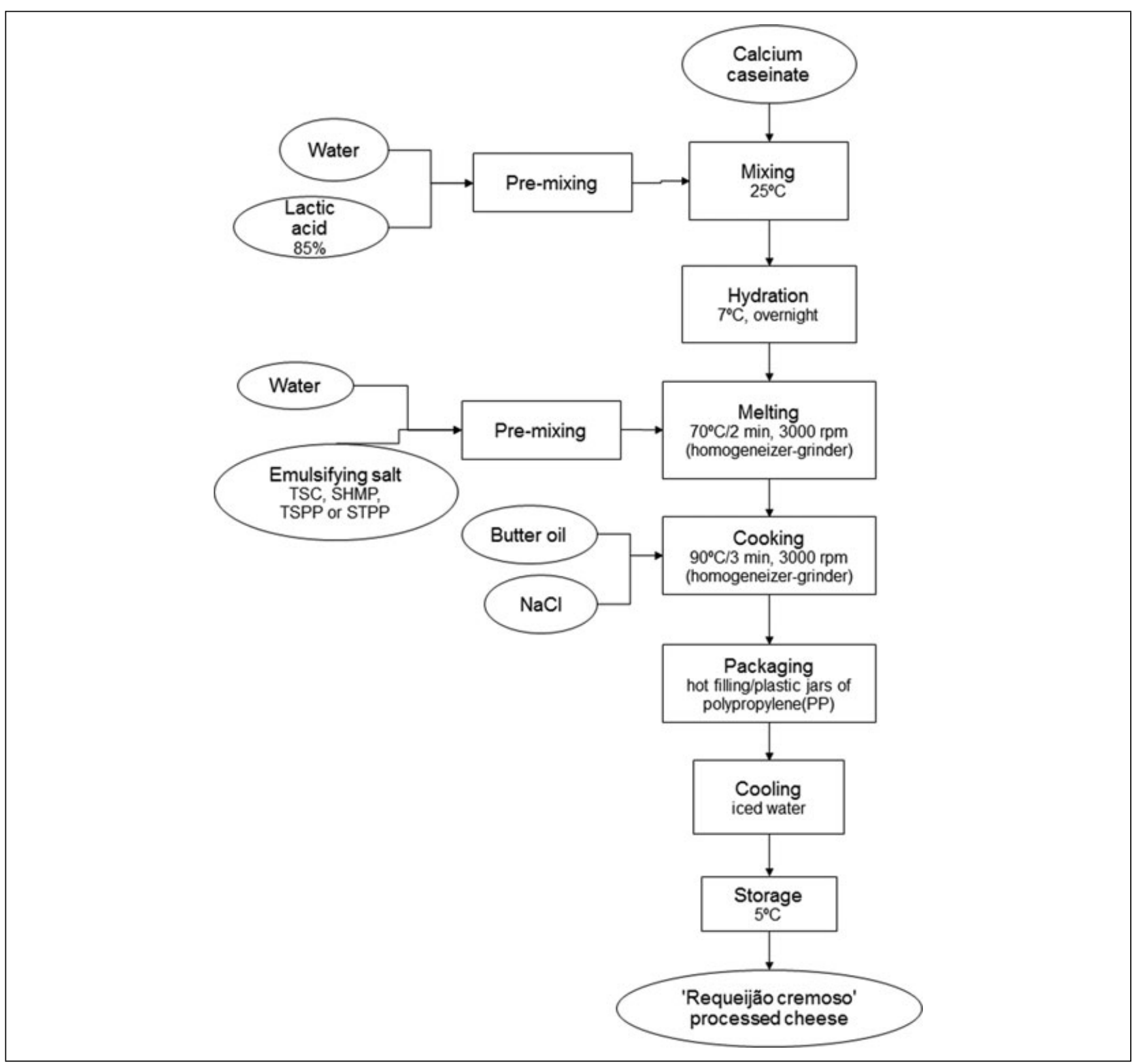

Figure 1-Schematic illustration showing the manufacturing stages of "requeijão cremoso" processed cheeses made with different emulsifying salts: TSC (trisodium citrate); SHMP (sodium hexametaphosphate); TSPP (tetrasodium pyrophosphate); and STPP (sodium tripolyphosphate). The amount of each ingredient was calculated and adjusted to result in a final product with $63 \%$ moisture, $10.5 \%$ protein, $1 \% \mathrm{NaCl}$, and $0.83 \%$ emulsifying salt. The amount of lactic acid added was that required to reduce $\mathrm{pH}$ of the mixture caseinate + water to 5.3. Font: Cunha and Viotto (2010). $209 \times 279 \mathrm{~mm}$ $(300 \times 300 \mathrm{DPI})$. 
acetone. The samples were dried in a CPD 030 critical point dryer (Bal-tec AG, Balzers, Liechtenstein), fractured at room temperature, mounted on aluminium stubs with silver glue, coated with gold $(240 \mathrm{~s} / 40 \mathrm{~mA})$ using the SCD 050 sputterer (Bal-tec AG, Balzers, Liechtenstein) and observed under the JEOL JSM5800LV scanning electron microscope (JEOL-USA, Inc., Peabody, Mass., U.S.A.) at $10 \mathrm{kV}$.

\section{Rheological properties}

The mechanical spectra of the samples were obtained using a Paar Physica MCR 300 rheometer (Anton Paar GmbH, Graz, Áustria), with a $5 \mathrm{~cm}$ diameter, $2^{\circ}$ stainless steel cone-plate system. The truncation of the cone (gap) was $100 \mu \mathrm{m}$. The temperature of the samples was maintained at $10^{\circ} \mathrm{C}$, on the bottom plate, by a Peltier system. Sufficient sample was held by a spatula, a second spatula was then used to gently push the sample on to the bottom plate of the rheometer. The plate was raised slowly to the measuring position. Excess samples were trimmed off the edges of the cone using a plastic spatula.

In the oscillatory tests, G' (elastic modulus), G" (viscous modulus), and $\eta^{*}$ (complex viscosity) were measured at frequencies ranging from 0.01 to $10 \mathrm{~Hz}$ at a strain of $0.3 \mathrm{~Pa}$, which was within the linear viscoelastic region (determined by preliminary experiments).

In the rotational tests, the flow curves of the samples were obtained using the controlled shear rate mode of the rheometer at a shear rate range of 0 to 100 per s. The total run time was 8 $\mathrm{min}$. The data for shear stress $(\tau)$ as a function of the deformation rate $(\mathrm{d} \gamma / \mathrm{d} t)$ were fitted to the power-law model $\tau=k(\mathrm{~d} \gamma / \mathrm{d} t)^{n}$, where $k$ is the consistency index and $n$ the flow behavior index.

\section{Experimental design}

A random block experimental design was adopted. The factor studied was the type of ES used (TSC, SHMP, STPP, and TSPP). Four trials were carried out in triplicate, giving a total of 12 experiments. The results were evaluated using the analysis of variance (ANOVA), using the Tukey test to verify differences between the means $(P<0.05)$. The analyses were performed using a statistical program (Minitab ${ }^{\circledR} 12.1$ for Windows, Minitab Inc., State College, Pa., U.S.A.).

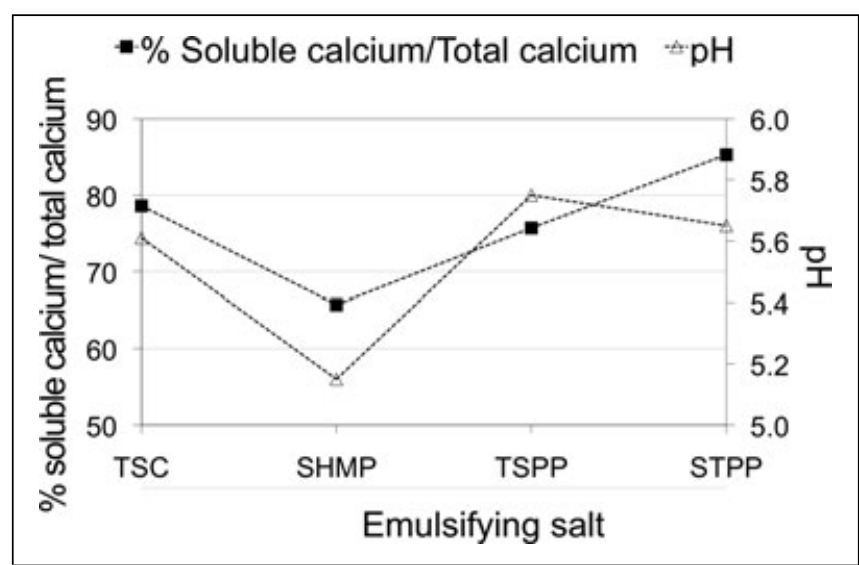

Figure 2-pH and percentage soluble calcium/total calcium of the processed cheeses as a function of the type of emulsifying salt: trisodium citrate (TSC); sodium hexametaphosphate (SHMP); tetrasodium pyrophosphate (TSPP); pentasodium tripolyphosphate (STPP). Adapted from previously reported results (Cunha and Viotto 2010). $209 \times 297 \mathrm{~mm} \mathrm{(300} \mathrm{x}$ $300 \mathrm{DPI})$.

\section{Results and Discussion}

\section{Characterization of the "requeijão cremoso" cheese}

The chemical compositions of "requeijão cremoso" cheeses have been previously reported by Cunha and Viotto (2010). At the end of manufacture, "requeijão cremoso" cheeses had the following mean composition: moisture $63.23 \pm 0.36 \%$, fat $23.82 \pm 0.46 \%$, fat in a dry wet basis $64.82 \pm 0.82 \%$, salt $1.05 \pm 0.04 \%$, protein $10.51 \pm 0.25 \%$, nonprotein nitrogen $0.02 \pm 0.00 \%$, and total calcium $160.3 \pm 1.5 \%$. The degree of casein dissociation for the cheeses made with SHMP, TSPP, TSC, and STPP were, respectively, $69.2 \pm 2.8 \%, 89.0 \pm 1.6 \%, 86.6 \pm$ $1.6 \%$, and $85.5 \pm 2.1 \%$. Figure 2 shows $\mathrm{pH}$ and percentage soluble calcium/total calcium of the processed cheeses as a function of the type of ES used (adapted from Cunha and Viotto 2010).

The $\mathrm{pH}$ and the degree of casein dissociation of the cheese manufactured with SHMP were significantly $(P<0.05)$ lower than those of the other cheeses. These findings are in agreement with the results reported by Dimitreli and others (2005), Dimitreli and Thomareis (2009), and Sádlíkova and others (2010). The value for the percentage soluble calcium/total calcium was also significantly $(P<0.05)$ lower for the SHMP cheese as compared to the others. In general, cheeses made with TSPP, TSC, and STPP showed a more similar composition, although slight differences could be observed, particularly with respect to $\mathrm{pH}$, which was higher for TSPP cheese than to TSC cheese, and to the percentage soluble calcium/total calcium, which was higher for STPP cheese than to the other 2 . The reasons for the differences found with respect to these parameters have been extensively discussed in an earlier study (Cunha and Viotto 2010).

\section{Microstructure of the "requeijão cremoso" cheese made with different ESs}

TSC, TSPP, STPP, and SHMP used as ESs gave an efficient emulsification for all processed cheese samples.

Figure 3 shows the microstructure $(5000 \times$ magnification $)$ of processed cheeses manufactured with TSC (a), SHMP (b), TSPP (c), and STPP (d). The following typical processed cheese structures can be seen in all samples: a continuous protein matrix permeated by fat globules and, eventually, by water (small irregular shaped spaces, not covered by protein). The fat globules presented predominantly spherical shapes, uniformly distributed throughout the protein matrix, in agreement with results previously obtained for processed cheeses (Tamime and others 1990; Mistry and Anderson 1993).

Cheese made with SHMP presented smaller fat globules than the other cheeses (Figure 3). Photomicrographs show also that cheeses made with SHMP and TSPP presented a more homogenous distribution, whilst cheese made with STPP and TSC presented a wider range of particle size. Previously reported data on the fat particle size distribution of the same cheeses, measured using a particle size analyser, showed similar results (Cunha and Viotto 2010).

The presence of a large number of small fat globules indicates that SHMP was more efficient in promoting fat emulsification, which seems contradictory since cheese made with SHMP also showed the lowest degree of casein dissociation. As discussed by Cunha and Viotto (2010), this apparently conflicting result could be explained by the hypothesis that, during manufacture, SHMP promoted an effective peptization of the casein, which sounds reasonable since the calcium binding capacity increases with the number of phosphate anions in the chain. The solubilization of 
casein allowed it to act as a true emulsifier, but after that probably occurred the formation of a new network, composed of re-associated casein and insoluble calcium phosphate. In the case of TSC, TSPP, and STPP, the re-association of the casein was limited, possibly because of the higher $\mathrm{pH}$ and the chemical nature of the salts, which explains the higher degrees of casein dissociation.

The greater homogeneity in particle size distribution found for TSPP cheese as compared to cheeses made with STPP and TSC have been also discussed by Cunha and Viotto (2010), and could be explained by the slightly higher $\mathrm{pH}$ showed by TSPP cheese (Figure 2). During manufacture, the higher $\mathrm{pH}$ improved the calcium sequestering ability of the salt (Guinee and others 2004; Dimitreli and others 2005), allowing casein to dissociate more effectively and to act as a more efficient emulsifier than in TSC or STPP cheeses. During cooling, a certain level of casein reassociation probably occurred for the 3 samples, but the extension and the mechanisms of re-association were possibly different depending on the type of salt, which would explain the results found for the degree of casein dissociation and the percentage soluble calcium/total calcium.

\section{Influence of the type of ES on rheological properties of "requeijão cremoso" cheese}

Oscillatory tests. Figure 4 shows the mechanical spectra of the processed cheeses manufactured with different ESs, whereas
Table 1 shows the mean values obtained for G', G", $\eta^{*}$, and phase angle $\left(G^{\prime \prime} / G^{\prime}\right)$ for the processed cheeses manufactured with different types of ES. The type of ES significantly influenced $(P<0.05)$ all the parameters evaluated.

The cheeses manufactured with TSC, TSPP, and STPP (Figure $4 \mathrm{a}, 4 \mathrm{c}$, and $4 \mathrm{~d}$ ) presented typical behavior of concentrated solutions: G" was greater than G' at low frequencies, G' was greater than $G^{\prime \prime}$ at higher frequencies, and $\eta^{*}$ was strongly dependent on the frequency. At higher frequencies, there was insufficient time for the intermolecular bonds to break during the oscillation period, and thus the network behaved like a gel, presenting characteristics more typical of solids than of liquids (G'> G'). At lower frequencies, the molecular chains had sufficient time to undergo re-arrangements and flow.

It can be seen that the frequency in which transition occurred was smallest for the cheese manufactured with TSPP, followed by the cheeses manufactured with TSC and STPP, respectively. This means that the molecular interactions were probably stronger in the cheese manufactured with TSPP than in those manufactured with TSC or STPP, much lower frequencies being required to allow for molecular re-arrangements to occur. This result can be explained by the size and distribution of the fat globules. In the cheeses manufactured with STPP and TSC, the fat globules were larger and showed less uniformity in size than in the cheese manufactured with TSPP (see Figure 3). The emulsified fat globules covered

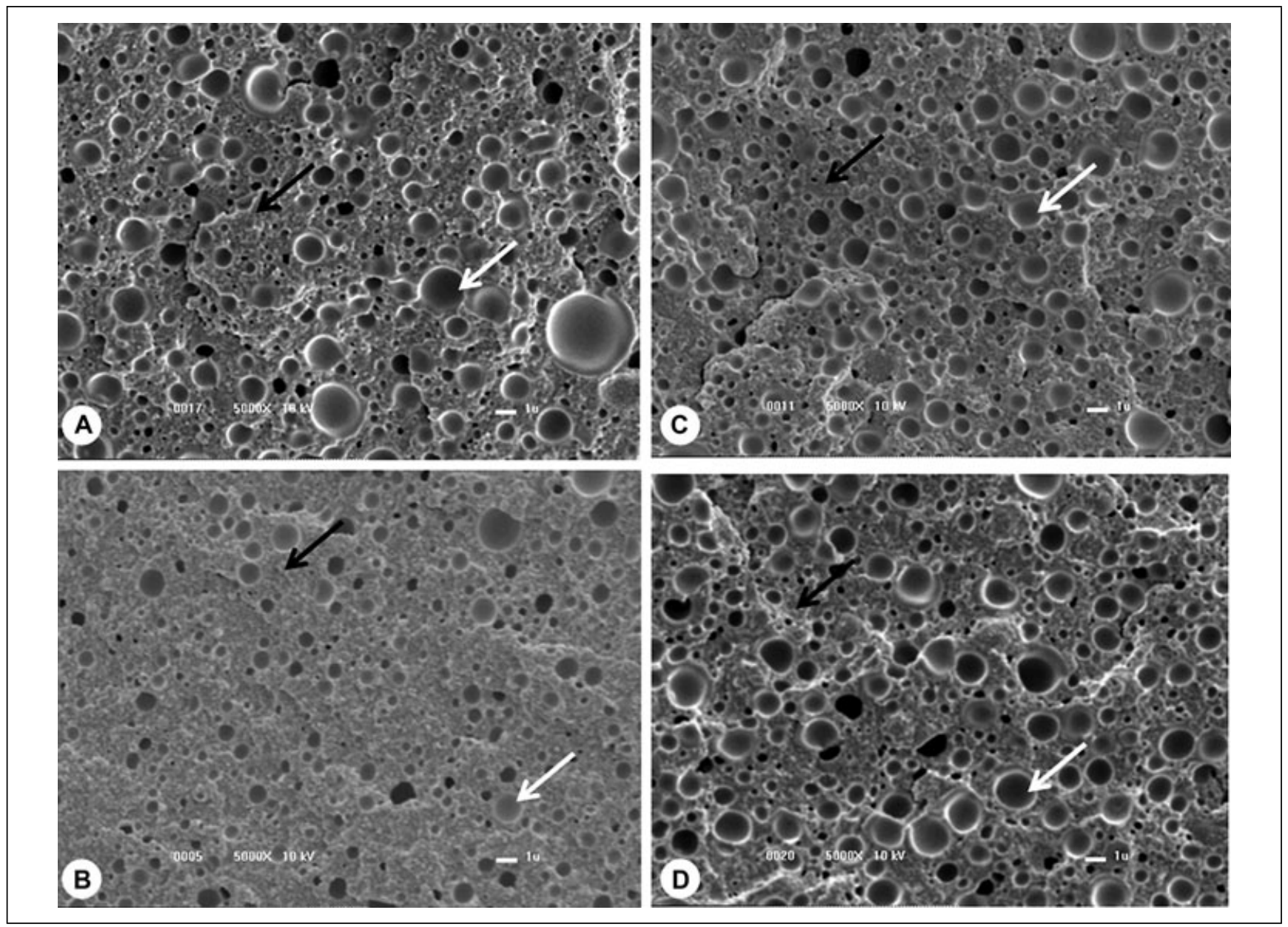

Figure 3-Scanning electron microscopy of "requeijão cremoso" cheeses manufactured with different emulsifying salts: (a) trisodium citrate (TSC), (b) sodium hexametaphosphate (SHMP), (c) tetrasodium pyrophosphate (TSPP), (d) pentasodium tripolyphosphate (STPP). 5000 x, at $10 \mathrm{kV}$. Black arrows indicate protein matrix and white arrows indicate fat globules. Scale bar $=1 \mu \mathrm{m} .150 \times 113 \mathrm{~mm}(300 \times 300 \mathrm{DPI})$. 
with casein function as large protein (or pseudo protein) particles, which are incorporated into the protein network (Marchesseau and others 1997; Michalski and others 2002; Guinee and others 2004), increasing gel strength. The larger the diameter and the lesser the uniformity of the fat globules, the smaller the surface area available for interaction and the less the amount of protein-protein interactions, justifying the higher frequencies of transition found in the cheeses manufactured with TSC and STPP as compared to those manufactured with TSPP. In the cheese manufactured with STPP (Figure 4d), the frequency in which the transition from "liquid" to "solid" behavior occurred was much higher than in

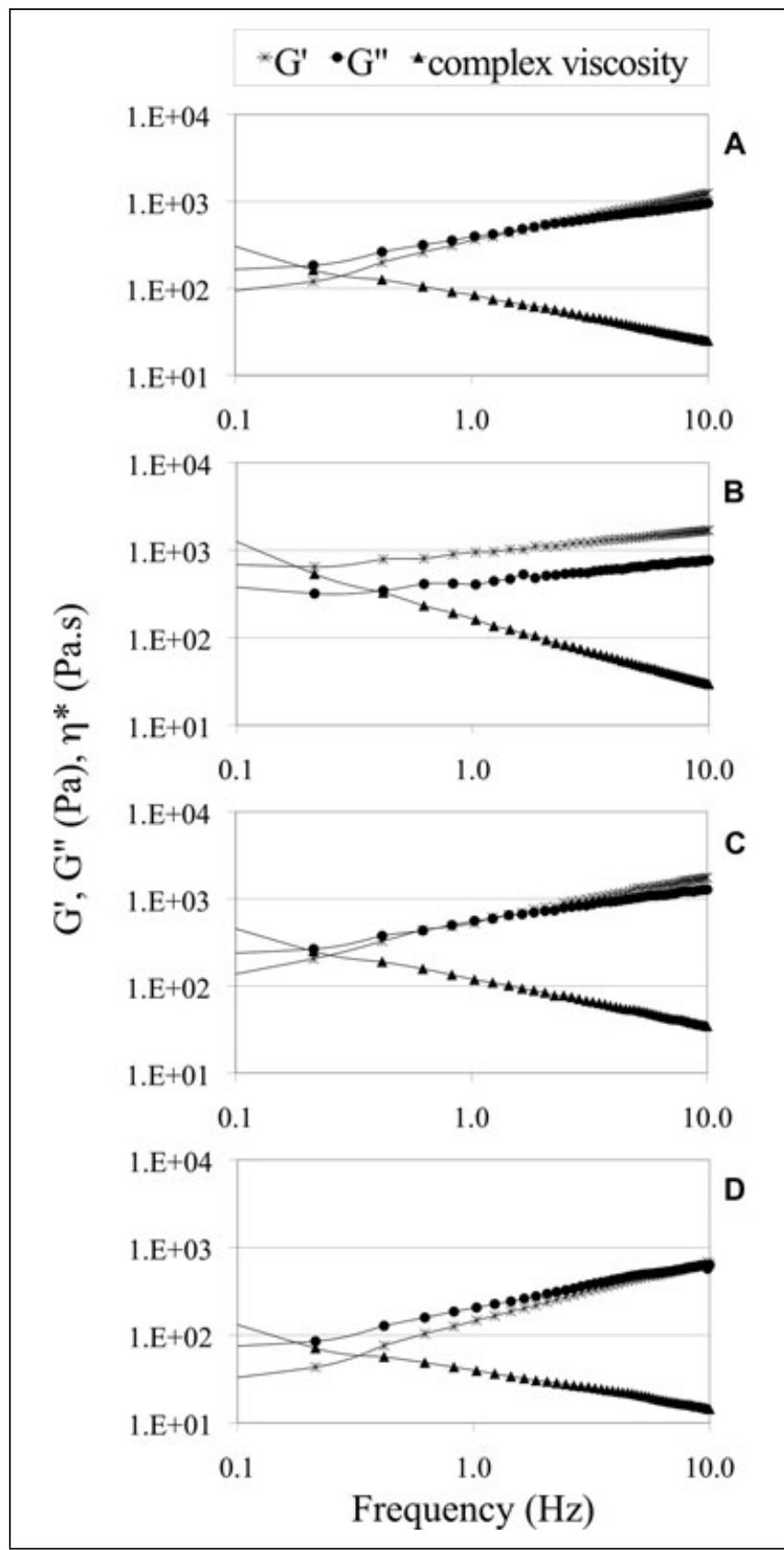

Figure 4-Mechanical spectra of the processed cheeses manufactured with different emulsifying salts: (a) trisodium citrate (TSC); (b) sodium hexametaphosphate (SHMP); (c) tetrasodium pyrophosphate (TSPP); (d) pentasodium tripolyphosphate (STPP). The results showed refer to the 2nd replicate. $209 \times 297 \mathrm{~mm}(300 \times 300 \mathrm{DPI})$. the other cheeses, indicating that, in this sample, the molecular interactions were even weaker.

The cheese manufactured with SHMP (Figure 4b) showed behavior typical of a weak gel: G' greater than G" throughout the frequency range, both moduli being little dependent on the frequency, and $\eta^{*}$ fell sharply with the increase in frequency. This indicated that the cheese manufactured with SHMP had a more elastic structure with stronger molecular interactions than the other samples. The small size of the fat particles found in this sample must have contributed to this, since the smaller the diameter, the greater the number of protein-protein bonds.

The type of ES significantly influenced the phase angle (G'/G') (Table 1). In decreasing order of G"/G', the cheeses manufactured were as follows: STPP $>$ TSC $>$ TSPP $>$ SHMP. A high value for the phase angle indicates a less structured and more peptized protein network. The result found could be explained by the size of the fat globules of the samples. The cheese manufactured with SHMP showed the smallest fat globule diameter, which made the network firmer and more structured, with a low value for G"/G'.

The cheeses manufactured with STPP and TSC showed lower values for G' (elastic modulus) and $\eta^{*}$ (complex viscosity) as compared to the others (Table 1). This result could also be explained by the larger size and reduced uniformity of the fat globules found in these samples (see Figure 3).

The size of the fat globules was not the only factor that influenced the elastic modulus, since, despite the difference in size of the fat globules of the cheeses manufactured with TSPP and SHMP (Figure 3), there was little difference between them with

Table 1-Mean values $(n=3)$ for G' (elastic modulus), G' (viscous modulus), $\eta^{*}$ (complex viscosity), and G'/G' (phase angle) of the processed cheeses manufactured with different emulsifying salts: sodium hexametaphosphate (SHMP), tetrasodium pyrophosphate (TSPP), trisodium citrate (TSC), and pentasodium tripolyphosphate (STPP). The reported values are related to the frequence $5.11 \mathrm{~Hz}$. Values in parenthesis indicate standard deviation related to 3 replicates.

\begin{tabular}{lcccc}
\hline Sample & SHMP & TSPP & TSC & STPP \\
\hline G' $^{\prime}(\mathrm{Pa})$ & $1493^{\mathrm{a}}$ & $1616^{\mathrm{a}}$ & $779^{\mathrm{b}}$ & $427^{\mathrm{b}}$ \\
& $(97)$ & $(129)$ & $(48)$ & $(22)$ \\
$\mathrm{G}^{\prime \prime}(\mathrm{Pa})$ & $730^{\mathrm{b}}$ & $1196^{\mathrm{a}}$ & $680^{\mathrm{b}}$ & $464^{\mathrm{b}}$ \\
& $(64)$ & $(122)$ & $(77)$ & $(15)$ \\
$\eta^{*}(\mathrm{~Pa} . \mathrm{s})$ & $51.8^{\mathrm{a}}$ & $62.7^{\mathrm{a}}$ & $32.2^{\mathrm{b}}$ & $19.6^{\mathrm{b}}$ \\
& $(4.6)$ & $(5.9)$ & $(3.5)$ & $(0.8)$ \\
$\mathrm{G}^{\prime \prime} / \mathrm{G}^{\prime}\left(^{\circ}\right)$ & $0.49^{d}$ & $0.74^{\mathrm{c}}$ & $0.88^{\mathrm{b}}$ & $1.09^{\mathrm{a}}$ \\
& $(0.03)$ & $(0.04)$ & $(0.05)$ & $(0.03)$ \\
\hline
\end{tabular}

$\overline{\mathrm{a}, \mathrm{b}, \mathrm{c}, \mathrm{d}}$ Means with the same letter, in the same line, do not differ significantly $(P>0.05)$.

Table 2-Mean values $(n=3)$ for $\boldsymbol{n}$ (flow behavior index), $\boldsymbol{k}$ (consistency index) and $R^{2}$ of the processed cheeses manufactured with different emulsifying salts: sodium hexametaphosphate (SHMP), tetrasodium pyrophosphate (TSPP), trisodium citrate (TSC), and pentasodium tripolyphosphate (STPP). Values in parenthesis indicate standard deviation related to 3 replicates. Experimental data obtained in rotational tests (shear stress $x$ shear rate) were fitted to the power-law model: $\tau=k(d y / d t)^{n}$, where $\tau=$ shear stress $(\mathbf{P a}), k=$ consistency index $\left(\mathbf{P a} . s^{n}\right),(\mathrm{d} y / \mathbf{d} t)=$ shear rate (per s) and $n=$ flow behavior index (dimensionless).

\begin{tabular}{lcccc}
\hline Sample & SHMP & TSPP & TSC & STPP \\
\hline$n$ & $0.24^{\mathrm{b}}$ & $0.24^{\mathrm{b}}$ & $0.30^{\mathrm{a}, \mathrm{b}}$ & $0.36^{\mathrm{a}}$ \\
& $(0.03)$ & $(0.03)$ & $(0.01)$ & $(0.02)$ \\
$k\left(\right.$ Pa. $\left.^{n}\right)$ & $242.7^{\mathrm{c}}$ & $701.7^{\mathrm{a}}$ & $409.0^{\mathrm{b}}$ & $232.9^{\mathrm{c}}$ \\
& $(23.0)$ & $(66.8)$ & $(33.9)$ & $(18.8)$ \\
$R^{2}$ & 0.979 & 0.928 & 0.955 & 0.970 \\
\hline a.b.c.c
\end{tabular}

a,b,c Means with the same letter, in the same line, do not differ significantly $(P>0.05)$. 
respect to G'. In SHMP cheese, the high values for G' were due to the combined effects of small fat droplets, low degree of casein dissociation and low percentage soluble calcium/ total calcium, which resulted in a more elastic protein network. In cheese made with TSPP, on the other hand, the high values of G' could be explained both by a better emulsification in comparison with TSC and STPP cheeses, and by its higher $\mathrm{pH}$ in comparison with SHMP cheese. Increasing $\mathrm{pH}$ increases the negative charge of the protein molecules, causing their repulsion and expansion. In process cheese, ionic repulsion in the $\mathrm{pH}$ range 5.7 to 6.0 , instead of totally dispersing proteins, enhances different type of interactions, such as noncovalent bonds (hydrogen bonds, hydrophobic, and electrostatic interactions) (Marchesseau and others, 1997), thus increasing elasticity.

Rotational tests. Table 2 shows the mean values for $n$ and $k$ for the cheeses manufactured with different ESs. The type of ES significantly $(P<0.05)$ influenced the 2 parameters evaluated.

All the cheeses presented $n$ values below 1, indicating that the apparent viscosity decreased with increase in the deformation rate applied, that is, they presented the behavior of pseudoplastic fluids. The cheese manufactured with STPP showed the highest value for $\mathrm{n}$, indicating that the proteins were freer to orientate themselves in the direction of flow than in the cheeses manufactured with TSPP and SHMP. This result is in agreement with the less structured protein network showed by this sample in oscillatory measurements (Table 1). Cheese made with TSC presented an intermediate value for $n$, meaning that its protein network was slightly firmer than that of STPP cheese but less structured than those of SHMP or TSPP cheeses, which is consistent with the intermediate value of G"/G' showed by this sample (Table 1).

The cheese manufactured with SHMP showed a low value for $k$ when compared to cheese made with TSPP and TSC. The consistency index $(k)$ is related to the viscosity, which, in processed cheeses, is attributed mainly to the intermolecular interactions and attractive forces between the protein particles (Dimitreli and Thomareis 2004). The low value of $k$ for SHMP cheese could be attributed to its lower $\mathrm{pH}$ value (see Figure 2), which resulted in a decrease in the hydration and in volume of the protein particles, increasing the distance between them, thus decreasing the viscosity. On the other hand, the cheese manufactured with TSPP showed the highest value for $k$. This could be attributed both to its high $\mathrm{pH}$ value when compared to SHMP, and to its fat particle distribution, which was more regular than that of STPP and TSC (see Figure 3).

Cheeses manufactured with SHMP and STPP presented similar values for $k$, but very different values for $\mathrm{n}$. This result shows that, despite presenting completely different viscoelastic behavior (as indicated by the $n$ values), both samples had similar viscosities, which is in agreement with the values of G" found in oscillatory tests (Table 1). It does not mean, however, that the protein interactions and attractive forces in both samples were of the same nature. As already explained, in SHMP cheese, reduced viscosity was due to the low $\mathrm{pH}$. In STPP cheese, the low values for $k$ could be explained by its high percentage of soluble/total calcium (Figure 2), meaning that less calcium was bonded to the casein network and, therefore, a smaller number of molecular interactions occurred between the proteins, thus decreasing viscosity.

\section{Conclusions}

The type of ES influenced the microstructure and the rheological properties of processed cheese. SHMP was the most efficient fat emulsifier, resulting in the network with the smallest fat globules size. The cheeses manufactured with TSC, TSPP, and STPP behaved like concentrated solutions, while the cheese manufactured with SHMP exhibited weak gel behavior and the lowest values for the phase angle G"/G'. This means that the protein network with the largest amount of molecular interactions was obtained for the cheese made with SHMP, which is in agreement with the highest degree of fat emulsification found for this sample. Rotational viscometry indicated that all the samples behaved like pseudoplastic fluids. Because of the strongest network structure of cheese made with SHMP, it also presented a low value for the flow behavior index, meaning that viscosity was more dependent on shear rate. With respect to the consistency index, the cheese manufactured with TSPP showed the highest value as compared to the other samples, indicating a higher viscosity that could be attributed to the combined effect of its high $\mathrm{pH}$ and homogeneous fat particle size distribution. For the cheese industry, an improved knowledge about how each type of ES affects the structure and the rheological properties of processed cheese will permit a most appropriate selection of the blend of ESs and a better control of the texture characteristics of the final product.

\section{Acknowledgements}

This research was carried out with the financial support of the State of São Paulo Research Foundation, FAPESP, Brazil and the Brazilian National Research Council, CNPQ, Brazil.

\section{References}

ABIQ: Associação Brasileira das Indústrias de Queijo [Internet]. Queijos: Mercado Total Brasileiro. São Paulo: ABIQ. Available from: http://www.abiq.com.br. Acessed 2008 Aug 7 .

Berger W, Klostermeyer H, Merkenich K, Uhlmann G. 1989. Processed cheese manufacture: a JOHA guide. Ladenburg, Germany: BK Ladenburg. 238p.

Cunha CR, Viotto WH. 2010. Casein peptization, functional properties, and sensory acceptance of processed cheese spreads made with different emulsifying salts. J Food Sci 75:C113-20.

Dimitreli G., Thomareis AS. 2009. Instrumental textural and viscoelastic properties of processed cheese as affected by emulsifying salts and in relation to its apparent viscosity. Int J Food Properties 12:261-75

Dimitreli G., Thomareis AS. 2004. Effect of temperature and chemical composition on processed cheese apparent viscosity. J Food Eng 64:265-71.

Dimitreli G, Thomareis AS, Smith PG. 2005. Effect of emulsifying salts on casein peptization and apparent viscosity of processed cheese. Int J Food Eng 1:1-15.

Gallina D.A. 2005. Influência do tratamento UHT na qualidade do requeijão cremoso tradicional e light [PhD Thesis]. Campinas, SP, Brazil: State University of Campinas. 235 p. Available from: Biblioteca Digital da Unicamp, code: vtls000375328. http://www.fea.unicamp.br/ alimentarium/ver_documento.php?did=161. Accessed Dec 20, 2011

Guinee TP, Caric M, Kaláb M. 2004. Pasteurized processed cheese and substitute/imitation cheese products. In: Fox PF, McSweeney PLH, Cogan TM, Guinee TP, editors. Cheese: chemistry, physics and microbiology, Vol. 2: Major cheese groups. 3rd ed. London: Elsevier Ltd. p 349-94.

Marchesseau S, Gastaldi E, Lagaude A, Cuq JL. 1997. Influence of $\mathrm{pH}$ on protein interactions and microstructure of process cheese. J Dairy Sci 80:1483-9.

Michalski MC, Cariou R, Michel F, Garnier C. 2002. Native vs. damaged milk fat globules: membrane properties affect the viscoelasticity of milk gels. J Dairy Sci 85:2451-61.

Mistry VV, Anderson DL. 1993. Composition and microstructure of commercial full-fat and low-fat cheeses. Food Struct 12:259-66.

Sádlíkova I, Bunka F, Budinský P, Barbora V, Pavlínek V, Hoza I. 2010. The effect of selected phosphate emulsifying salts on viscoelastic properties of processed cheese. Food Sci Technol 43:1220-5

Tamime AY, Kaláb M, Davies G, Younis MF. 1990. Microstructure and firmness of processed cheese manufactured from Cheddar cheese and skim milk powder cheese base. Food Microstructure 9:23-37.

Zehren VL, Nusbaum DD. 1992. Process cheese. Madison, Wis.: Cheese Reporter Publishing Co. $363 \mathrm{p}$.

(6) 